\title{
PROBLEMAS ARITMÉTICOS COMO ELEMENTOS DA MATEMÁTICA DO ENSINO
}

\author{
ARITHMETIC PROBLEMS AS ELEMENTS OF \\ THE MATHEMATICS OF TEACHING
}

\author{
Luciane de Fatima Bertini ${ }^{1, *}$ \\ Wagner Rodrigues Valente ${ }^{2}$
}

\begin{abstract}
RESUMO: Este texto trata do tema da formação de professores que ensinam matemática em perspectiva histórica, tendo como interesse a matemática presente na formação docente e no ensino. De modo mais específico, intenta-se responder à pergunta: Como os problemas aritméticos se constituíram em um dos elementos que articulam a matemática da formação de professores e a do ensino escolar? As conclusões revelam os processos e dinâmicas estabelecidos entre uma matemática a ensinar e uma matemática para ensinar, ambas constituintes de uma matemática do ensino.
\end{abstract}

Palavras-chave: História da educação matemática. Formação de professores. Saberes docentes. Problemas. Matemática do ensino.

\begin{abstract}
This text discusses the formation of mathematics teachers from a historical perspective, focusing on the mathematics present in teacher training, as well as in the teaching activity. More specifically, we aim at answering the question: How did arithmetic problems become one of the elements that articulate the mathematics in teacher training and in school teaching? The conclusion reveals the processes and dynamics established between the mathematics to teach and the mathematics for teaching, both of which are part of a mathematics of teaching.
\end{abstract}

Keywords: History of mathematics education. Teacher training. Teaching knowledge. Problems. Mathematics of teaching.

\footnotetext{
1.Universidade Federal de São Paulo - Instituto de Ciências Ambientais, Químicas e Farmacêuticas Departamento de Ciências Exatas e da Terra - São Paulo (SP), Brasil.

2.Universidade Federal de São Paulo - Escola de Filosofia, Letras e Ciências Humanas - Departamento de Educação - São Paulo (SP), Brasil.

*Autora correspondente: luciane.bertini@unifesp.br

Número temático organizado por Wagner Rodrigues Valente
} 


\section{Introdução}

Que matemática deve estar presente na formação dos futuros professores? A pergunta tem orientado uma gama enorme de pesquisas. Este estudo trata desta questão em perspectiva histórica e, ainda, restringe-se ao primeiro nível de escolaridade. Assim, a pergunta ganha a seguinte formulação: Que matemática foi sendo elaborada ao longo do tempo para estar presente na formação dos futuros professores, tendo em vista as necessidades do seu ensino nos primeiros anos escolares? Essa questão conduz o desenvolvimento de projeto temático, ${ }^{1}$ de largo intervalo temporal, reunindo um coletivo de pesquisadores que mobiliza variada empiria documental, incluindo livros didáticos, arquivos escolares, Imprensa pedagógica, cadernos de alunos e professores, legislação do ensino e da formação de professores, entre outros materiais.

Partindo, inicialmente, da interrogação sobre a matemática da formação de professores e do seu ensino, este texto focará em um aspecto dessa matemática: os problemas aritméticos. Assim, de modo específico, este artigo intenta dar resposta à questão: Como os problemas aritméticos se constituíram um dos elementos que articulam a matemática da formação de professores e a do ensino escolar?

\section{Cultura Escolar, Forma Escolar, Disciplina Escolar e Escolarização de Saberes}

As pesquisas de caráter histórico que temos desenvolvido sobre o tema da formação de professores têm mobilizado categorias como forma escolar, cultura escolar, disciplina escolar e escolarização dos saberes. Tais ferramentas conceituais mostraram-se adequadas para abordar o que denominamos matemática do ensino, assunto específico de estudos que colocam os saberes no centro da discussão e, mais especificamente, de estudos que envolvem a matemática presente no ensino e na formação de professores. A matemática do ensino distingue-se daquela representante do campo disciplinar matemático. Liga-se à formação de professores e ao ensino. Antes, porém, de aprofundarmos a discussão sobre os estudos históricos e a caracterização da matemática do ensino, consideramos importante realizar um détour teórico, de modo a retomar as categorias que nos servem de lentes de observação das dinâmicas e dos processos de produção de novos saberes.

Vincent, Lahire e Thin (2001), a partir de uma análise sócio-histórica, propõem conceituar forma escolar como um modo específico de socialização: o modo escolar. Reconhecendo que a forma escolar constitui processos de lutas e transformações e, portanto, é fruto de um processo histórico, os autores destacam alguns traços que a caracterizam: "a constituição de um universo separado para a infância; a importância das regras na aprendizagem; a organização racional do tempo; a multiplicação e repetição de exercícios, cuja função consiste em aprender e aprender conforme as regras [...]" (VINCENT; LAHIRE; THIN, 2001, p. 37-38). Para os autores, esse modo de socialização é, ainda, baseado em processos de objetivação e codificação de saberes por meio da escrita.

Também considerando os processos históricos, Julia (2001) defende a existência de uma cultura escolar, que se constitui a partir de suas relações conflituosas ou pacíficas com outras culturas. Três eixos são considerados adequados pelo autor para a análise da cultura escolar como objeto histórico: as normas e finalidades que regem a escola; o papel desempenhado pela profissionalização do trabalho de educador; e a análise dos conteúdos ensinados e das práticas escolares. A discussão desse último eixo é desenvolvida por Julia com base nos estudos de André Chervel sobre disciplinas escolares.

Tomando resultados de pesquisas sobre o ensino da gramática francesa, Chervel (1990) conclui que essa matéria não pode ser entendida como uma vulgarização das ciências ditas de referência, afirmando 
que ela foi criada pela própria escola, na escola e para a escola. Assim, o autor discute as relações entre as disciplinas escolares, as ciências de referência e a pedagogia, problematizando as ideias de "disciplinavulgarização" e de "pedagogia-lubrificante".

Os estudos de Hébrard (1990) trazem para a discussão outros elementos, ao considerar as instituições dedicadas às primeiras aprendizagens e o processo de escolarização dos saberes elementares. Para o autor, a trilogia do ler-escrever-contar tem como base duas culturas profissionais antigas: a dos clérigos e a dos mercadores. A primeira delas está mais diretamente ligada ao par ler/escrever; já "a conquista do escrever/contar remete antes à complexificação dos processos de produção e de circulação de mercadorias, à progressiva ingerência, nessas atividades privadas, de administrações locais ou distantes" (HÉBRARD, 1990, p. 102). Os elementos apresentados por esse autor chamam a atenção para a participação de práticas sociais e profissionais no processo de escolarização dos saberes.

A partir das conceituações de forma, cultura e disciplina escolar e da ideia de escolarização dos saberes, é possível pensar a escola como um espaço de criação, com saberes, regras e finalidades que lhes são próprios, ainda que constituídos em um processo histórico e em relação ao que lhe é externo. Nessa perspectiva, é possível pensar em produções constituídas pela própria escola, na escola e para a escola a partir dos relações conflituosas e pacíficas com outras culturas (JULIA, 2001); com a pedagogia, como uma das ciências de referência (CHERVEL, 1990); com práticas sociais e profissionais (HÉBRARD, 1990); e como resultado de processos de objetivação e codificação (VINCENT; LAHIRE; THIN, 2001).

Feito esse breve détour, avaliamos que a contribuição dos autores mencionados é fundamental para as análises que realizamos sobre a produção histórica da matemática envolvida na formação de professores e no ensino dos primeiros anos escolares. Tomando tais referenciais, analisamos a constituição do que chamamos matemática do ensino, que envolve aspectos do ensino e da formação de professores. De modo mais destacado, valemo-nos das análises de Julia (2001), que enfatiza serem o corpo docente e a formação de professores aspectos essenciais em discussões sobre a cultura escolar. Tal autor defende que "normas e práticas não podem ser analisadas sem se levar em conta o corpo profissional dos agentes que são chamados a obedecer a essas ordens e, portanto, a utilizar dispositivos pedagógicos encarregados de facilitar sua aplicação" (JULIA, 2001, p. 11). O autor destaca, ainda, três elementos fundamentais à constituição de uma cultura escolar: espaço escolar, cursos graduados em níveis; e corpo profissional específico (JULIA, 2001, p. 14). Assim, para Julia (2001) a cultura escolar diz respeito ao ensino, mas se constitui, entre outras coisas, na relação com a formação de professores. Desse modo, ponderamos que, ao tratar da matemática no ensino e na formação de professores, considerando a matemática do ensino, situamo-nos em meio aos estudos que tratam das produções da cultura escolar.

\section{Matemática a Ensinar, Matemática para Ensinar e Matemática do Ensino}

Hofstetter e Schneuwly (2017), ao discutirem processos históricos de transformação de saberes do ensino e da formação de professores, tomam os saberes formalizados como tema central e identificam dois tipos constitutivos de saberes referidos à profissão docente: os saberes $a$ ensinar, como objeto do trabalho docente, e os saberes para ensinar, como as ferramentas desse trabalho. Para esses autores, os saberes para ensinar são os

[...] saberes sobre "o objeto" do trabalho de ensino e de formação (sobre os saberes $a$ ensinar e sobre o aluno, o adulto, seus conhecimentos, seu desenvolvimento, as maneiras de aprender 
etc.), sobre as práticas de ensino (métodos, procedimentos, dispositivos, escolha dos saberes $a$ ensinar, modalidades de organização e gestão) e sobre a instituição que define o seu campo de atividade profissional (planos de estudos, instruções, finalidades, estruturas administrativas e políticas etc.) (HOFSTETTER; SCHNEUWLY, 2017, p. 134).

Considerando essas análises e dando centralidade ao saber do professor que ensina matemática, foram elaboradas as categorias de matemática $a$ ensinar e matemática para ensinar. A primeira é vista como aquela presente no ensino: o que professor deverá ensinar a seus alunos. Essa matemática é fruto de complexos processos históricos de elaboração, analisados, por exemplo, pela ótica da história das disciplinas escolares (CHERVEL, 1990). De outra parte, a segunda é constituída historicamente no embate entre o campo disciplinar matemático, as ciências da educação e o campo profissional da docência e se refere à matemática que o professor deverá saber para ensinar a primeira (BERTINI; MORAIS; VALENTE, 2017).

A elaboração dessas categorias - matemática a ensinar e matemática para ensinar -, respectivamente, como objeto e ferramenta do trabalho do professor, leva em conta a ideia de que a matemática não é considerada invariável diante da didática e das metodologias de ensino. Parte-se do princípio de que a matemática do ensino e da formação de professores muda com o passar do tempo.

De outra parte, há que se ponderar sobre o fato de que os conceitos elaborados por Hofstetter e Schneuwly (2017) são apropriados e tomados por autores brasileiros, ressalvando-se que

[...] caberia mencionar distinções possíveis de serem feitas para os termos "saber para ensinar matemática" e "matemática para ensinar". No primeiro caso, ao que parece, poderiam ser arrolados um conjunto [sic] de saberes colocados na grade de formação de professores. Todo esse conjunto comporia o que se poderia entender por "saberes para ensinar matemática”, eles seriam os saberes de formação do professor. De modo diferente, a "matemática para ensinar" refere-se à objetivação de um saber matemático [...]. Tal saber já contém, na sua própria caracterização, concepções de ensino, de aprendizagem, do papel da escola num dado tempo histórico etc. (BERTINI; MORAIS; VALENTE, 2017, p. 68).

Essas opções teóricas, longe de serem frutos de desdobramentos lógicos, idealizados, ancoram-se na empiria da realidade concreta, pois colocam em evidência embates e tensões entre campos disciplinares e o campo profissional da docência no processo de produção e sistematização dos saberes envolvidos no ensino e na formação de professores. É desse ponto que o presente artigo segue propondo discussões sobre as relações estabelecidas entre matemática do ensino, cultura escolar e formação de professores.

Desde logo, caberia a distinção entre "ensino de matemática" e matemática do ensino. A primeira expressão aponta para interesses didáticos. Talvez seja possível considerar que se trate dos desafios que o campo disciplinar matemático enfrenta quando se interessa pelo ensino e sua transmissão para crianças e adolescentes no meio escolar.

De outra parte, aqui entende-se que:

[...] a matemática do ensino interessa-se prioritariamente por questões epistemológicas. [...] Tal análise leva em consideração os aspectos envolvidos na formação de professores e no ensino ministrado numa dada época. Mobiliza documentação dirigida aos alunos e também textos que orientam o trabalho dos professores (MORAIS; BERTINI; VALENTE, 2021). 
Desse modo, ao interessar-se por questões epistemológicas, tem destaque o processo histórico de produção da matemática $a$ ensinar e da matemática para ensinar. Mais do que isso: no âmbito das tensões que envolvem as dinâmicas de mudanças da cultura escolar, enfatizamos o modo como tais matemáticas se articulam ao longo do tempo. Assim, a matemática do ensino representa a articulação entre a matemática $a$ ensinar e a matemática para ensinar, entre objeto e ferramenta de trabalho do professor.

Sendo a matemática do ensino representativa da articulação entre a matemática $a$ ensinar e a matemática para ensinar, ela está relacionada tanto ao espaço escolar como àqueles de formação de professores, envolvendo normas e finalidades desses dois espaços em articulação. Pesquisas que envolvem a matemática do ensino são desenvolvidas, então, em um ambiente descontínuo, reunindo, no âmbito da cultura escolar, também a formação de professores em cada tempo histórico. Assim, a matemática $a$ ensinar e a matemática para ensinar são constituídas a partir das relações que a escola historicamente mantém com culturas que lhe são externas e a partir das relações que a formação matemática de professores mantém historicamente com a matemática $a$ ensinar.

Esse processo produtivo de novos saberes se dá nesse espaço descontínuo que congrega, no seio da cultura escolar, ensino e formação. Tal espaço é movido por tensões entre campos disciplinares (matemática, ciências da educação) e campo profissional da docência. A escola não fará tudo que o campo profissional da docência quer que ela faça; não fará também tudo o que quer o campo disciplinar; tampouco o que ditam as ciências da educação. Da mesma maneira, a formação de professores não se relacionará com as demandas desses campos passivamente, em desconexão com as práticas de ensino. Os saberes e os significados a eles atribuídos serão construídos no seio dessas tensões, que revelam, a cada tempo, diferente peso relativo a cada um desses campos.

\section{Os Problemas como Elementos da Matemática do Ensino}

Para as discussões sobre matemática do ensino, considerou-se a cultura escolar um espaço descontínuo, que articula o ensino e a formação de professores. O estudo dos elementos constituintes dessa matemática é um desafio enfrentado pelos pesquisadores interessados nas análises que caracterizam epistemologicamente os saberes envolvidos no ensino e na formação de professores. Alguns deles foram já realizados, tendo em vista, especificamente, os problemas de aritmética. São exemplos desses trabalhos as pesquisas de Souza (2017) e Bertini (2019).

Souza (2017) utilizou como fontes as revistas pedagógicas paulistas publicadas entre 1890 e 1930 . No estudo, a autora identifica cinco tendências nos discursos veiculados pelas revistas quanto ao uso de problemas aritméticos: ausência como indício; problemas como sinônimo de exercícios; problemas como símbolo da modernidade pedagógica; aritmética para ensinar problemas; e problemas a partir dos centros de interesse.

Sobre a tendência “aritmética para ensinar problemas", Souza (2017) defende que, a partir de 1920, começam a aparecer nos artigos orientações que consideram os problemas um conteúdo a ser ensinado nas aulas de aritmética, havendo inclusive propostas de sequências para ensiná-los. Assim, os problemas de aritmética configuram elementos integrantes da aritmética como um saber $a$ ensinar e, de forma articulada, passam a constituir aspecto para a formação de professores, isto é, elementos de uma aritmética para ensinar.

As discussões sobre uma "aritmética para ensinar problemas" têm início, de acordo com Souza (2017), no artigo de uma professoranda, termo utilizado para as estudantes das Escolas Normais. No artigo, a autora, Anna Nogueira Ferraz, menciona que os pressupostos por ela apresentados foram retirados do livro Cultivo y Desarollo de Aptitud Matemática del Niño, escrito por Victor Mercante. ${ }^{2}$ Assim, é possível 
pensar que, a partir das propostas do campo da educação, via tratados pedagógicos, como a obra de Victor Mercante, foi sendo sistematizada uma matemática para ensinar problemas. Das discussões do âmbito da formação, parte-se para o ensino. Sobre esse aspecto, as revistas indicarão que ensinar problemas deverá ser um conteúdo a ser tratado nas aulas.

Na mesma perspectiva, Bertini (2019), ao analisar cadernos de alunos franceses utilizados entre 1890 e 1936, identifica os problemas como um saber a ser ensinado, considerando sua centralidade nos cadernos, sua relação com outras atividades de ensino de aritmética e, principalmente, a existência de "problemas-tipo" com "soluções-tipo", que compunham as atividades ao longo do ano e eram muitas vezes o único objeto de avaliação.

A pesquisa realizada por Bertini (2019), ao tomar como principal fonte para os estudos os cadernos escolares, envolve, de forma mais próxima, elementos da cultura escolar e de suas relações como as normatizações e as orientações para o ensino que circulavam naquele tempo na França. As justificativas apresentadas pela autora para a conclusão de que os problemas constituem saber a ser ensinado ligam-se justamente às articulações entre formação e ensino; envolvem a identificação de que, tanto nas propostas dos livros didáticos quanto nos cadernos escolares, predominavam os "problemas-tipo" e, assim, deveriam ser ensinadas aos alunos as "soluções-tipo". Além disso, nos cadernos, os problemas ganham centralidade nas atividades registradas, principalmente, nas avaliações realizadas. Assim, é possível pensar que os problemas, como saber a ser ensinado nas escolas, efetivam-se em articulação com orientações para o ensino de problemas - pensar os problemas como um elemento produzido na articulação entre a matemática $a$ ensinar e a matemática para ensinar, como uma matemática do ensino.

As pesquisas citadas mostram que, em determinados tempos históricos, os problemas assumem o status de um saber a ser ensinado. Assim, os alunos precisam aprender a resolver problemas e os professores, a ensinar os alunos a resolvê-los. Esses resultados indicam uma mudança nas relações estabelecidas entre a aritmética $a$ ensinar e aritmética para ensinar, do ponto de vista dos problemas aritméticos. No princípio, os problemas aritméticos apresentavam-se como uma forma de verificação das aprendizagens sobre as quatro operações ou como uma ferramenta para o ensino delas. Quando os problemas passam a se constituir como elementos da aritmética $a$ ensinar, desenvolvem-se, na formação de professores, imperativos que demandam do professor incorporar um saber para ensinar problemas aritméticos; em específico, demanda-se que uma aritmética para ensinar problemas deverá integrar a sua formação. Na relação estabelecida entre ensino dos problemas aritméticos e formação de professores para ensinar esses problemas, surge um novo elemento da matemática do ensino.

\section{Considerações Finais}

Nesse ponto, caberia retomarmos a questão orientadora deste estudo: Como os problemas aritméticos se constituíram em um dos elementos que articulam a matemática da formação de professores e do ensino escolar?

No âmago de sua própria formulação, a questão indica a perspectiva de análise histórica interessada na relação entre formação de professores e exercício profissional da docência. Isso leva as investigações a considerarem, por exemplo, um tratamento mais alargado do conceito de cultura escolar, tendo em vista, principalmente, as ponderações de Dominique Julia (2001). Assume-se que a formação de professores para os primeiros anos escolares e o exercício da docência mantêm relações que, entre outros elementos, produzem saberes.

Os problemas aritméticos, nos movimentos observados nas pesquisas citadas, em determinado momento, passam de ferramenta a objeto de ensino. Antes entendidos e utilizados como uma ferramenta para 
o ensino das operações, passam a ser considerados, em si mesmos, objeto do ensino. A relação entre ferramenta e objeto de ensino certamente não será sempre a mesma; poderá ser estabelecida de diferentes formas, a partir das tensões estabelecidas entre os campos profissional e disciplinar, em cada tempo, e a partir de como a cultura escolar resolve, em cada época, as tensões envolvidas entre o ensino e a formação de professores.

Considerando, por exemplo, os resultados apresentados por Souza (2017), é possível identificar elementos que permitem análises sobre essas relações. A autora analisa discursos que circularam por meio de artigos publicados em revistas pedagógicas. No período analisado, as revistas pedagógicas são identificadas como um importante veículo de formação de professores, ao divulgarem orientações oficiais e práticas educacionais consideradas exemplares (NOGUEIRA, 2007). No caso das discussões sobre o uso de problemas nas aulas de aritmética, Souza identifica que a maior parte dos autores exercia atividades profissionais ligadas ao ensino e/ou à formação de professores: "professores, diretores, inspetores de ensino e diretores de órgãos públicos" (2017, p. 51). Nos resultados da pesquisa de Bertini (2018) os elementos que permitem a discussão sobre a passagem dos problemas de ferramenta para objeto de ensino também colocam em destaque as relações entre ensino e formação de professores, neste caso, por meio da articulação entre as orientações para o ensino, lidas nos livros didáticos, e o ensino realizado nas escolas, lido nos cadernos escolares de alunos do ensino primário.

Com isso, volta-se à discussão dos processos de elaboração dos saberes docentes. A constituição desses saberes, conforme defendido por Hofstetter e Schneuwly (2017), envolve embates e tensões entre campos disciplinares e o campo profissional. Vale destacar que esses embates e tensões são entendidos como processos produtivos e constitutivos dos saberes do ensino e da formação de professores. Sendo assim, a constituição de uma matemática $a$ ensinar e de uma matemática para ensinar envolveriam embates e tensões entre o campo disciplinar matemática e o campo profissional docente. Valente, Bertini e Morais (2021) reconhecendo a consolidação da Educação Matemática como campo disciplinar a partir da década de 1980, propõem uma ampliação dos campos que, sob tensão produtiva, possibilitam a produção de novos saberes. No caso das matemáticas a ensinar e para ensinar, discutidas em pesquisas que analisam documentos pós-1980, caberia considerar as tensões entre os campos disciplinares (Matemática e Educação Matemática) e entre esses e o campo profissional (docência). Os autores destacam, ainda, que "essas tensões são múltiplas em cada tempo histórico, tendo cada uma delas peso relativo diferente em dada época” (VALENTE; BERTINI; MORAIS, 2021).

As análises anteriores vêm permitindo caracterizar elementos que integram o que denominamos matemática do ensino. Aqui, propomos discussões sobre o espaço em que esses embates e tensões ocorrem, o espaço de produção de saberes do ensino e da formação. Defende-se a ideia de que a matemática do ensino, representante das articulações entre a matemática $a$ ensinar e para ensinar, é produzida em um espaço descontínuo, no qual são estabelecidas articulações históricas entre a formação de professores e a prática profissional da docência.

Diferentemente de estudos cujo foco liga-se às preocupações didáticas, em que o campo disciplinar apresenta uma matemática a ser ensinada na escola, ponderamos que as pesquisas sobre a matemática do ensino levam-nos ao movimento dos processos e das dinâmicas que articulam, em cada tempo histórico, formação e docência. Tais processos e dinâmicas, no mais das vezes conflituosos, resultam na produção de novos saberes, novas matemáticas do ensino.

\section{Notas}

1. Projeto temático "A matemática na formação de professores e no ensino: processos e dinâmicas de produção de um saber profissional", financiado pela FAPESP, sob a coordenação de Wagner Rodrigues Valente e tendo como pesquisadoras associadas Luciane de Fatima Bertini, Neuza Bertoni Pinto e Rosilda dos Santos Morais. 
2. Nasceu na Argentina em 1870, formou-se na Escola Normal e iniciou sua carreira como professor em 1890. Trabalhou na Universidad de La Plata, ocupou cargos importantes no Ministerio de Justicia e Instrucción Pública e ajudou na reforma do ensino argentino, tendo como principal defesa o ensino laico. A obra Cultivo y Desarollo de Aptitud Matemática del Niño foi publicada por ele no ano de 1905 (SOUZA, 2019).

\section{Contribuições dos Autores}

Problematização e Conceitualização: Bertini LF, Valente WR; Metodologia: Bertini LF, Valente WR; Análise: Bertini LF, Valente WR; Redação: Bertini LF, Valente WR.

\section{REFERÊNCIAS}

BERTINI, L. F. Problemas de aritmética: participação na marcha de ensino e na relação com a vida prática (cadernos de alunos franceses, 1890 a 1936). BOLEMA - Boletim de Educação Matemática, Rio Claro, v. 33, n. 64, p. 613-634, 2019. https://doi.org/10.1590/1980-4415v33n64a08

BERTINI, L. F.; MORAIS, R. S.; VALENTE, W. R. A matemática a ensinar e a matemática para ensinar: novos estudos sobre a formação de professores. São Paulo: Editora Livraria da Física, 2017.

BORER, L. Saberes: uma questão crucial para a institucionalização da formação de professores. In: VALENTE, W.; HOFSTETTER, R. (orgs.). Saberes em (trans)formação: tema central da formação de professores. São Paulo: Editora Livraria da Física, 2017. p. 173-199.

CHERVEL, A. História das disciplinas escolares: reflexões sobre um campo de pesquisa. Teoria \& Educação, Porto Alegre, n. 2, p. 177-231, 1990.

CHERVEL, A. En quoi une culture peut-elle être scolaire? In: JACQUET-FRANCILLON, F.; KAMBOUCHNER, D. (dirs.). La crise de la culture scolaire. Paris: PUF, 2005. p. 77-85.

HÉBRARD, J. A escolarização dos saberes elementares na época moderna. Teoria \& Educação, Porto Alegre, n. 2, p. 65-110, 1990.

HOFSTETTER, R.; SCHNEUWLY, B. Saberes: um tema central para as profissões do ensino e da formação. In: VALENTE, W.; HOFSTETTER, R. (orgs.). Saberes em (trans)formação: tema central da formação de professores. São Paulo: Editora Livraria da Física, 2017. p. 113-172.

JULIA, D. A cultura escolar como objeto histórico. Revista Brasileira de História da Educação, Campinas, v. 1, n. 1, p. 9-43, jan./jun. 2001.

MORAIS, R. S.; BERTINI, L. F.; VALENTE, W. R. A matemática no ensino de frações. Uberaba: SBHMat, 2021. No prelo.

NOGUEIRA, F. H. G. A imprensa periódica educacional e as fontes de pesquisa para a história da educação. Sinergia, São Paulo, v. 8, n. 1, p. 60-65, jan./jul. 2007. Disponível em: http://ojs.ifsp.edu.br/index.php/ 
sinergia/issue/view/32. Acesso em: 27 out. 2020.

PINHEIRO, N. V. L. A aritmética sob medida: a matemática em tempos de pedagogia científica. 2017. $224 \mathrm{f}$. Tese (Doutorado em Ciências) - Escola de Filosofia, Letras e Ciências Humanas, Universidade Federal de São Paulo, São Paulo, 2017. Disponível em: https://repositorio.ufsc.br/handle/123456789/179942. Acesso em: 13 out. 2020.

SOUZA, A. F. Discursos para ensinar problemas aritméticos (São Paulo, 1890-1930). 2017. 135 f. Dissertação (Mestrado em Ciências) - Escola de Filosofia Letras e Ciências Humanas, Universidade Federal de São Paulo, São Paulo, 2017. Disponível em: Disponível em: https://repositorio.ufsc.br/ handle/123456789/178612\#: :text=Foi\%20poss\%C3\%ADvel\%20observar\%20nos\%20discursos,partir\%20 dos\%20centros\%20de\%20interesse. Acesso em: 28 out. 2020.

SOUZA, A. F. Problemas aritméticos e o ensino: orientações de Victor Mercante (Buenos Aires, 1905). In: ENCONTRO BRASILEIRO DEESTUDANTES DE PÓS-GRADUAÇÃO EMEDUCAÇÃO MATEMÁTICA, 23., 2019, São Paulo. Anais [...], 2019. p. 1-12. Disponível em: http://eventos.sbem.com.br/index.php/ EBRAPEM/EBRAPEM2019/paper/viewFile/299/558. Acesso em: 28 out. 2020.

VALENTE, W. R.; BERTINI, L. F.; MORAIS, R. S. Saber profissional do professor que ensina matemática analisado em perspectiva histórica: contribuições teórico-metodológicas a partir do estudo sistemático de uma pesquisa. Revista Brasileira de História da Educação, Campinas, v. 21, p. 1-20, 2021. https:// doi. org/10.4025/rbhe.v21.2021.e161

VINCENT, G.; LAHIRE, B.; THIN, D. Sobre a história e a teoria da forma escolar. Educação em Revista, Belo Horizonte, n. 33, jun. 2001.

Recebido: 16 Nov. 2020

Aceito: 06 Maio 2021

Editoras Associadas:

Alessandra Arce Hai e Ana Clara Bortoleto Nery 